\title{
RENDIMENTO DA PRODUÇÃO DE BALA DE BANANA EM UMA PEQUENA AGROINDÚSTRIA LOCALIZADA EM GUARAQUEÇABA-PR
}

\section{BANANA CANDY PRODUCTION IN A SMALL AGROINDUSTRY LOCATED IN GUARAQUEÇABA-PR}

\author{
Agenor MACCARI JÚNIOR ${ }^{1}$ \\ Jorge Luiz Moretti de SOUZA2* \\ Jefferson BITTENCOURT ${ }^{3}$
}

\begin{abstract}
RESUMO
O presente trabalho teve como objetivo analisar o rendimento das operações de descasque e cozimento da banana caturra (Grupo: Cavendish, Classe: 6 e 9, Subclasse: 4 e 5) para o processamento da bala de banana. O experimento foi realizado em uma pequena agroindústria, denominada Unidade de Transformação dos Produtos Agrícolas de Batuva (UTPA Batuva), construída para promover o desenvolvimento sustentável e agregar valor à produção de banana da comunidade de Batuva, localizada na Área de Proteção Ambiental de Guaraqueçaba-PR. Diversos estudos estão sendo conduzidos para otimizar a estrutura da unidade e capacitar agricultores para gerenciá-la. Neste trabalho, 41 formulações diferentes para produção da bala de banana foram testadas. As operações de descasque e cozimento foram avaliadas a partir de análises de regressão e correlação. Os resultados evidenciaram que: (a) As relações de rendimento seguiram tendências lineares; (b) Em média, $100 \mathrm{~kg}$ de banana in natura renderam 66,7 kg de polpa e 19,31 kg de bala; (c) Maiores rendimentos em relação à quantidade de polpa de banana por tempo de cozimento na produção de bala foram obtidos quando se trabalhou com a capacidade dos tachos acima do limite projetado.
\end{abstract}

Palavras-chave: Processamento; planejamento; descasque; cozimento.

\begin{abstract}
The objective of this work was to analyze the efficiency of the banana (Group: Cavendish, Class: 6 e 9; Subclass: 4 e 5) peeling and cooking operations in the candy production process. The experiment was carry out in a small agroindustry denominated UTPA Batuva, which was build to promote the sustainable development as well as to aggregate commercial value to the banana production from the Batuva's community, located in the Environmental Protection Area of Guaraqueçaba-PR. Several studies are being carried to optimize the agroindustry structure and to capacitate the farmers to manage it. In this work, 41 different formulations for banana candy production were tested. The banana peeling and cooking operations in the candy production process were evaluates with regression and correlation analyses. The results showed that: (a) The yield relationships followed linear tendencies; (b) In average, $100 \mathrm{~kg}$ of banana fresh fruit resulted in $66.7 \mathrm{~kg}$ of banana pulp and $19.31 \mathrm{~kg}$ of banana candy; (c) The candy production evaluated by the quantity of banana pulp versus cooking time was more efficient when the capacity of the pan worked above the limit projected.
\end{abstract}

Key-words: Processing; planning; banana peeling; banana cooking.

\footnotetext{
1 Engenheiro Agrônomo, Doutor em Tecnologia Pós-Colheita, Professor do DSEA / SCA / UFPR

${ }^{2}$ Engenheiro Agrícola, Doutor em Agronomia, Professor do Departamento de Solos e Engenharia Agrícola, Setor de Ciências Agrárias, Universidade Federal do Paraná (DSEA/SCA/UFPR). Rua dos Funcionários, 1540. Cep 80035-050, Curitiba, PR, Brasil. e-mail: jmoretti@ufpr.br *Autor para correspondência;

${ }^{3}$ Eng. Agrônomo, M.Sc em Tecnologia Pós-Colheita
} 


\section{INTRODUÇÃO}

A comunidade de Batuva está localizada no município de Guaraqueçaba, litoral norte do Estado do Paraná, junto à divisa dos Estados do Paraná e São Paulo e distante $30 \mathrm{~km}$ da sede do município. Formada por famílias que empregam mão de obra familiar, Batuva se caracteriza pela agricultura de subsistência, com a cultura da banana presente em $100 \%$ das propriedades (WALFLOR, 1999).

A bananicultura na região de Guaraqueçaba, inclusive Batuva, é de baixa tecnologia e a maior parte das propriedades não emprega insumos agrícolas. A produção obtida pelos produtores apresenta baixa qualidade e produtividade. Este fato, aliado as dificuldades de transporte, gera desvantagens na comparação entre a fruta produzida em Guaraqueçaba e o produto produzido em outras localidades do Paraná ou outros Estados (WALFLOR, 1999; KOBIYAMA et al., 1999).

No entanto, devido as característica do sistema de produção adotado, boa parte da banana produzida e processada em Batuva possui certificado de produto "orgânico" ou "biológico" concedido pelo Instituto Biodinâmico (IBD), conforme relata BITTENCOURT et al. (2004), que apontaram as vantagens econômicas decorrentes desta escolha. Isenta de contaminantes químicos, a banana produzida em Batuva possui propriedades sensoriais diferenciadas e pode alcançar maior valor de mercado na comercialização. Porém, mesmo com tais atributos, a comercialização da banana in natura apresenta inúmeras complicações, sendo a dificuldade de transporte uma das principais restrições.

A produção média de banana in natura comercializada pela comunidade de Batuva nos períodos de safra e entresafra fica em torno de 39,6 e 19,6 t mês ${ }^{-1}$, respectivamente. As cultivares mais plantadas são a nanica, nanicão, ouro e prata (MACCARI JR. e BITTENCOURT, 1999; SOUZA et al., 1999a).

As dificuldades enfrentadas pelos agricultores locais levaram a Universidade Federal do Paraná (UFPR) a executar o projeto de extensão "Desenvolvimento Sustentável em Guaraqueçaba", criado com a finalidade de propiciar melhores condições de desenvolvimento à comunidade local (WALFLOR, 1994). As ações culminaram com a criação de uma unidade agroindustrial para processar os produtos agrícolas da região, principalmente a banana, transformando-a em bala e passa (PORCHERON, 1995). A unidade foi construída pelos agricultores da comunidade sob orientação de técnicos e professores participantes do projeto. Posteriormente esta agroindústria foi chamada de "Unidade de Transformação dos Produtos Agrícolas de Batuva (UTPA Batuva)".

A tarefa de instalar a unidade agroindustrial mostrou desafios, em virtude de diversas limitações, como: o difícil acesso ao local (quase $100 \mathrm{~km}$ de estrada sem pavimentação); as exigências da legislação ambiental; e restrições quanto às fontes de energia.
Por ser atividade nova para a comunidade, foi necessário capacitá-la para o processamento do produto, o que exigiu ações de capacitação associadas à pesquisa e ao monitoramento do processo produtivo agrícola e agroindustrial. Do mesmo modo, o certificado de produto orgânico exigiu o desenvolvimento de tecnologia adequada, tema de pesquisas publicadas por BITTENCOURT et al. (2004), TSUCHIDA et al. (2003) e MACCARI JR. e BITTENCOURT (1999). No caso da bala de banana, as dificuldades de aquisição de insumos orgânicos na região, necessários para a elaboração de produtos certificados, levaram ao desenvolvimento de uma formulação diferenciada. A formulação foi desenvolvida buscando suprimir o uso de aditivos como acidulantes (ácido cítrico) ou espessantes (pectina). Isto tornou necessário aumentar o tempo de cozimento para que a concentração de sólidos atingisse ponto ideal, dando viscosidade e acidez adequadas ( $\mathrm{pH}$ inferior a 4,5).

A experiência de alguns autores mostrou que é imprescindível à realização de práticas experimentais que visem quantificar e aprimorar as operações dos processos produtivos, buscando reduzir "o longo trabalho de preparação, dedicação, erros e acertos" (TAGLIARI, 1997).

Devido à relevância das informações dispostas anteriormente, o presente trabalho de pesquisa teve como objetivo, analisar o rendimento das operações de descasque e cozimento da banana (Grupo: Cavendish, Classe: 6 e 9, Subclasse: 4 e 5) para o processamento da bala de banana da UTPA Batuva.

\section{MATERIAL E MÉTODOS}

O processamento da banana em bala de banana foi realizado na Unidade de Transformação de Produtos agrícolas de Batuva (UTPA Batuva), localizada na Área de Proteção Ambiental de Guaraqueçaba-PR, à uma latitude de 25018' S, longitude $48^{\circ} 21^{\prime} \mathrm{W}$-GR e 10 metros de altitude. Maiores informações sobre as instalações da UTPA Batuva podem ser encontrados em SOUZA et al. (1999a) e SOUZA et al. (1999b).

Segundo a classificação do PBMH e PIF (2006), a banana produzida na região da UTPA Batuva e utilizada no trabalho para fazer a bala de banana foi identificada como: (a) Grupo - Cavendish (nanica); (b) Classe - 6 e 9; (c) Subclasse - 4 e 5, segundo a escala de maturação de Von Loesecke. As bananas de melhor qualidade (Classe superior a 12) foram destinadas para a fabricação de banana passa, seguindo os procedimentos de rotina adotados na unidade, descritos por TSUCHIDA et al. (2003) e MACCARI JR. e BITTENCOURT (1999).

Os dados sobre o processo produtivo foram colhidos ao longo de um ano nas instalações da agroindústria. Os testes foram conduzidos pela equipe de manipuladores da unidade, monitorados por pesquisadores da UFPR, tendo como meta selecionar a melhor formulação para adoção na 
planta industrial. Deste modo, considerando o objetivo do estudo e as limitações de infra-estrutura, para a avaliação dos resultados foram utilizados equipamentos e métodos disponíveis na própria unidade. Assim, 41 formulações diferentes para produção da bala de banana foram avaliadas. Os parâmetros básicos adotados para análise de rendimento das operações de descasque e cozimento da banana foram:

- Peso das frutas in natura: este parâmetro foi determinado para cada caixa de banana, sendo as pencas pesadas em balança eletrônica. Os pesos obtidos foram somados obtendo-se o valor do "peso das frutas in natura por caixa";

- Peso da polpa: as bananas previamente pesadas foram descascadas e novamente pesadas, determinando-se o peso das frutas sem casca, parâmetro denominado de "peso da polpa";

- Tempo de cozimento: tempo cronometrado, correspondendo o período entre a carga do tacho com as bananas até o momento em que a massa atingiu o ponto desejado;

- Bala produzida: a quantidade de bala produzida em cada tacho foi determinada através de pesagem em balança eletrônica.

O procedimento empregado na produção da bala de banana na UTPA Batuva baseou-se nas atividades rotineiras desenvolvidas dentro da agroindústria e nas descrições e apontamentos realizados nos trabalhos de MACCARI JR. e BITTENCOURT (1999) e SOUZA et al. (1999a), sobre as atividades de recepção e processamento da banana na própria unidade e na região de Guaraqueçaba.

As frutas utilizadas nas análises para verificação do rendimento foram retiradas de lotes de matéria-prima processados na agroindústria. As frutas amostradas chegaram à UTPA acomodadas em caixas de madeira com $22 \mathrm{~kg}$ de fruta, colhidas ainda verde (subclasse 1 e 2, conforme escala de maturação de Von Loesecke), estádio inadequado para a produção de doce, bala e passa. A maturação foi realizada empregando o sistema tradicional da região, no qual as caixas com as frutas foram depositadas em uma estufa - uma sala de alvenaria com $30 \mathrm{~m}^{2}$ de área. Após a acomodação das caixas, a estufa foi fechada e vedada, sendo realizada queima de álcool em seu interior. Foram necessários três dias para o completo amadurecimento das frutas (BITTENCOURT et al., 2004; MACCARI JR. e BITTENCOURT, 1999).

Realizado o amadurecimento, as frutas possuindo maturação entre 5 e 7 (escala de Von Loesecke) foram levadas para a sala de manipulação para realização das operações de despencamento e descascamento da banana. Estas operações foram realizadas manualmente, utilizando-se apenas facas inox, seguindo os procedimentos de rotina que são empregados da agroindústria. Logo após, a polpa de banana seguiu para uma sala contendo dois tachos de cobre, cada um possuindo capacidade de $120 \mathrm{~kg}$ de polpa de banana, local em que foi feito o cozimento. Os tachos foram assentados sobre uma estrutura de alvenaria e dotados de sistema de pá mexedora acionada por motor elétrico. O aquecimento foi feito com fogareiro de alta pressão de 18 caulins (MACCARI JR. e BITTENCOURT, 1999).

Apenas os ingredientes polpa de banana e açúcar entraram na composição da bala de banana. A Tabela 1 apresenta as quantidades de polpa e açúcar utilizados nas 41 formulações testadas no presente trabalho. A formulação utilizada buscou suprimir o uso de aditivos como acidulantes (ácido cítrico) ou espessantes (pectina) visando minimizar as dificuldades de aquisição de insumos orgânicos na região, necessários para a elaboração de produtos certificados. 
MACCARI JÚNIOR, A. et al. Rendimento da produção de bala de banana...

TABELA 1 - Testes de rendimento das operações de descasque e cozimento da banana, para o processamento da bala de banana na UTPA Batuva.

\begin{tabular}{|c|c|c|c|c|c|c|}
\hline Testes & $\begin{array}{c}\text { Banana in } \\
\text { natura } \\
(\mathrm{kg})\end{array}$ & $\begin{array}{c}\text { Polpa de } \\
\text { Banana } \\
(\mathrm{kg})\end{array}$ & $\begin{array}{l}\text { Rendi- } \\
\text { mento } \\
(\%)\end{array}$ & $\begin{array}{c}\text { Açúcar } \\
(\mathrm{kg})\end{array}$ & $\begin{array}{c}\text { Tempo de } \\
\text { cozimento } \\
\text { (minuto) }\end{array}$ & $\begin{array}{c}\text { Bala } \\
\text { produzida } \\
(\mathrm{kg})\end{array}$ \\
\hline 1 & 167 & 93,00 & 55,69 & 3,00 & 690 & 27,00 \\
\hline 2 & 123 & 88.00 & 71.54 & 3.64 & 550 & - \\
\hline 3 & 162 & 100,00 & 61,73 & 3,00 & 660 & 28,00 \\
\hline 4 & 143 & 93,00 & 65,03 & 3,00 & 690 & 22,00 \\
\hline 5 & - & 77,00 & - & 2,00 & 660 & 23,00 \\
\hline 6 & - & 99,00 & - & 3,00 & 660 & 26,50 \\
\hline 7 & 107 & 77,00 & 71,96 & 4,56 & - & 22,30 \\
\hline 8 & 114 & 92,00 & 80,70 & 4,02 & 855 & 24,80 \\
\hline 9 & 128 & 99,50 & 77,73 & 6,09 & 960 & 27,00 \\
\hline 10 & 144 & 68,00 & 47,22 & 4,04 & 660 & 21,00 \\
\hline 11 & 140 & 82,00 & 58,57 & 4,56 & 630 & 23,00 \\
\hline 12 & 130 & 77,00 & 59,23 & 4,30 & 670 & 22,70 \\
\hline 13 & 125 & 81,00 & 64,80 & 4,58 & 720 & 24,30 \\
\hline 14 & - & 78,00 & - & 4,30 & 660 & 21,00 \\
\hline 15 & - & 110,00 & - & 3,30 & 600 & 33,50 \\
\hline 16 & - & 110,00 & - & 5,50 & 630 & 32,50 \\
\hline 17 & - & 55,00 & - & 3,25 & 510 & 14,40 \\
\hline 18 & 135 & 77,00 & 57,04 & 4,61 & 650 & 22,00 \\
\hline 19 & 123 & 73,50 & 59,76 & 5,20 & 818 & 22,62 \\
\hline 20 & - & 118,00 & - & - & - & 35,00 \\
\hline 21 & - & 103,00 & - & - & - & 29,40 \\
\hline 22 & 107 & 77,70 & 72,62 & 4,50 & 720 & 23,30 \\
\hline 23 & 104 & 76,20 & 73,27 & 4,58 & 780 & 22,00 \\
\hline 24 & 137 & 88,00 & 64,23 & 5,10 & 630 & 27,50 \\
\hline 25 & 131 & 101,00 & 77,10 & 5,70 & 660 & 27,00 \\
\hline 26 & 121 & 88,00 & 72.73 & 4,44 & 620 & 25.60 \\
\hline 27 & 212 & 157.00 & 74.06 & 7.70 & 750 & 42.00 \\
\hline 28 & 243 & 154,00 & 63,37 & 8,58 & 570 & 42,00 \\
\hline 29 & 157 & 88,00 & 56,05 & 2,50 & 570 & 25,00 \\
\hline 30 & 138 & 87,00 & 63,04 & 5,52 & 675 & 27,00 \\
\hline 31 & 115 & 80,00 & 69,57 & 4,80 & 710 & 22,00 \\
\hline 32 & 204 & 169,00 & 82,84 & 10,10 & 840 & 51,75 \\
\hline 33 & 273 & 180,00 & 65,93 & 10,20 & 540 & 51,00 \\
\hline 34 & 118 & 77,00 & 65,25 & 2,00 & 630 & 23,00 \\
\hline 35 & 162 & 86,00 & 53,09 & 4,94 & 645 & 24,30 \\
\hline 36 & 144 & 90,00 & 62,50 & 5,35 & 550 & 26,50 \\
\hline 37 & 174 & 88,00 & 50,57 & 4,84 & 690 & 25,40 \\
\hline 38 & 230 & 135,00 & 58,70 & 7,85 & 950 & 38,00 \\
\hline 39 & 70 & 51.90 & 74.14 & 4,36 & 480 & 15.30 \\
\hline 40 & - & 77,00 & - & 3,77 & 580 & 23,25 \\
\hline 41 & 180 & 132,00 & 73,33 & 7,51 & 600 & 40,10 \\
\hline Menor valor & 70 & 51,90 & 47,22 & 2,00 & 480 & 14,40 \\
\hline Maior valor & 273 & 180,00 & 82,84 & 10,20 & 960 & 51,75 \\
\hline Média & 149 & 95,95 & 65,73 & 4,88 & 670 & 27,60 \\
\hline Desvio padrão & 44 & 28,57 & 8,89 & 1,94 & 108 & 8,31 \\
\hline C.V. (\%) & 29 & 29,78 & 13,53 & 39,86 & 16 & 30,10 \\
\hline
\end{tabular}

O tempo de cozimento foi determinado visualmente, empregando práticas de rotina na unidade face o objetivo do trabalho, observando-se a consistência da massa obtida pelo cozimento da polpa. Atingindo o ponto desejado, a massa foi retirada e trabalhada, dando-se a forma desejada, característica do produto bala de banana (MACCARI JR. e BITTENCOURT, 1999).

Os parâmetros básicos coletados na fabricação da bala de banana, tais como peso das frutas in natura, peso de polpa, tempo de cozimento e peso da bala, foram organizados e avaliados em análises de regressão, correlação e diagramas de dispersão, seguindo as recomendações de PEREIRA e ARRUDA (1987). Com o auxílio de uma planilha eletrônica, foram realizadas análises de regressão linear, logarítmica, polinomial, potencial, exponencial e média móvel. A melhor equação foi escolhida a partir da relação mais estreita (maior coeficiente de correlação). Foram realizadas análises entre: (a) Banana in natura $(\mathrm{kg})$ vs Polpa de banana $(\mathrm{kg})$; (b) Polpa de banana $(\mathrm{kg})$ vs Bala de banana $(\mathrm{kg})$; (c) 
Banana in natura $(\mathrm{kg})$ vs Bala de banana $(\mathrm{kg})$; (d) Polpa de banana $(\mathrm{kg})$ vs Tempo de cozimento (minuto) - valores não agrupados; (e) Polpa de banana (kg) vs Tempo de cozimento (minuto) valores agrupados em sete intervalos de classe; (f) Bala de banana $(\mathrm{kg})$ vs Rendimento $\left(\mathrm{kg} \mathrm{min}{ }^{-1}\right)$ sendo o rendimento calculado pela relação entre peso de bala de banana $(\mathrm{kg})$ e o respectivo tempo de cozimento (minuto).

\section{RESULTADOS E DISCUSSÃO}

Os parâmetros básicos obtidos na fabricação da bala de banana com a realização das 41 formulações testadas na UTPA Batuva encontramse apresentadas na Tabela 1.

A relação percentual (\%) entre banana in natura e polpa de banana (rendimentos da Tabela 1) apresentou os seguintes valores: $65,73 \%$ de média $(s=8,89), 82,84 \%$ para o maior valor e $47,22 \%$ para o menor valor. Apesar de não ter sido realizado um delineamento experimental prévio, tendo sido as amostras de banana in natura coletadas ao acaso para cada teste, baseando-se nos limites de coeficiente de variação apresentados por FERREIRA (1991) (muito homogêneo: CV inferior a 10\%; homogêneo: CV entre $10 \%$ a $15 \%$; baixa homogeneidade: CV entre $15 \%$ e $20 \%$ ), verifica-se que o CV obtido para os rendimentos (CV $=13,53 \%)$ apresentou homogeneidade entre os lotes. Parte da variação observada para o rendimento entre os testes pode ter ocorrido em função do ponto de maturação (CHACÓN et al., 1997; WILLS et al., 1984), uma vez que este foi determinado visualmente.
Contrastando-se o rendimento médio $(65,73 \%)$ obtido no presente trabalho (Tabela 1$)$ com os obtidos por outros autores que também pesquisaram o rendimento da banana nanica com casca totalmente amarela (subclasse 6), é possível verificar que: JESUS et al. (2004) encontraram um rendimento $4,1 \%$ maior $(69,83 \%)$, RODRIGUEZ (1994) encontrou um rendimento $0,94 \%$ maior (66,67\%) e CHACÓN et al. (1997) comentam que os rendimentos podem variar entre $61,16 \%$ e $66,50 \%$. No entanto, é importante observar que o trabalho de JESUS et al. (2004), apesar de consistente tecnicamente, foi realizado em escala laboratorial e utilizou nos testes apenas 18 bananas in natura. Os pesos da banana in natura e polpa, apresentados na Tabela 1, constituem também um parâmetro específico da região de Batuva-PR. A banana in natura utilizada no trabalho de JESUS et al. (2004) foi proveniente de Cruz das Almas-BA, e RODRIGUEZ (1994) utilizou matéria prima adquirida diretamente do produtor da região de Morretes-PR, que se encontra distante $100 \mathrm{~km}$ de Batuva-PR.

A Figura 1 apresenta um diagrama de dispersão obtido a partir da relação entre as quantidades, em peso, de polpa e banana in natura. A melhor relação foi obtida para a equação de regressão linear $(Y=0,6229 X+4,416)$, com coeficiente de determinação $\left(R^{2}\right)$ igual a 0,7998 . Desta forma, pode-se constatar, em média, que 100 $\mathrm{kg}$ de banana in natura da região transformam-se em aproximadamente $66,7 \mathrm{~kg}$ de polpa de banana.

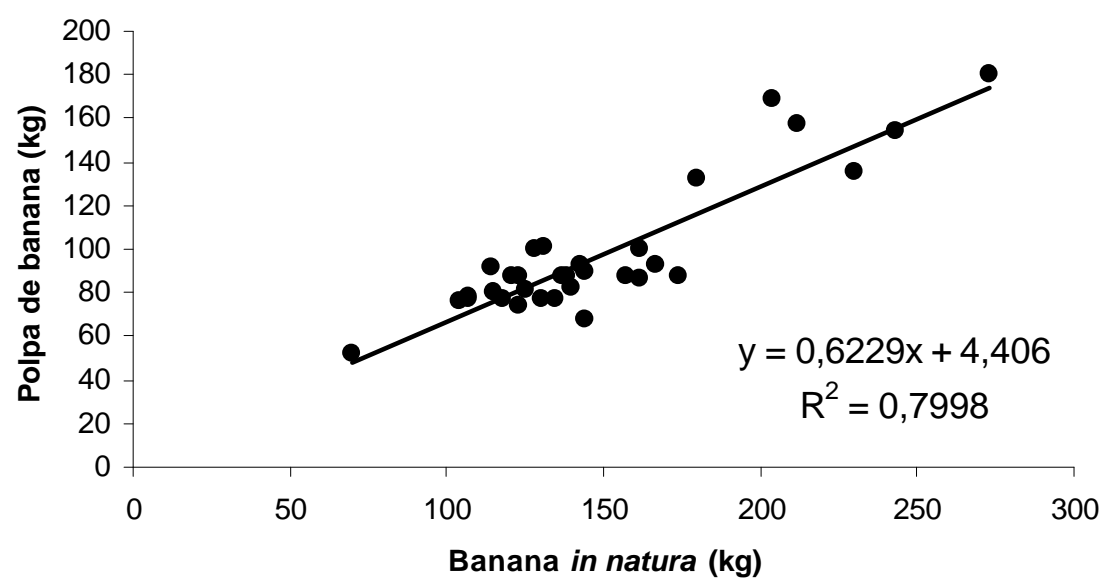

FIGURA 1 - Diagrama de dispersão obtido da relação entre os valores correspondentes de peso de polpa de banana vs banana in natura.

Os dados contidos na Tabela 1 permitiram determinar através de um diagrama de dispersão os rendimentos da transformação de diferentes quantidades de polpa de banana em bala (Figura 2). A relação entre as quantidades (peso) também mostrou tendência linear $(Y=0,2822 X+0,4668)$, com coeficiente de determinação $\left(R^{2}\right)$ igual a 0,9643 . Logo, pode-se dizer que $28,69 \mathrm{~kg}$ de bala de banana são produzidos aproximadamente a partir de $100 \mathrm{~kg}$ de polpa de banana. 


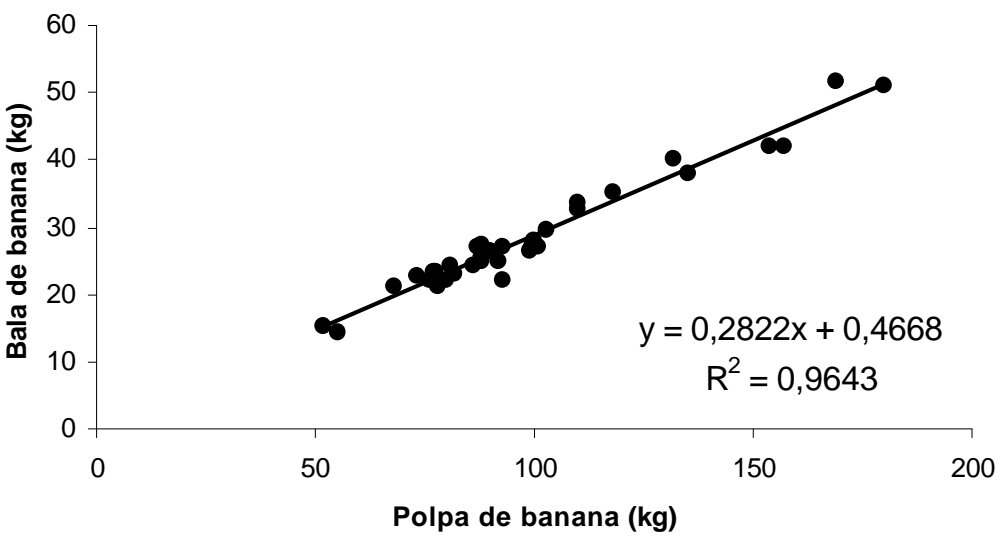

FIGURA 2 - Diagrama de dispersão obtido da relação entre os valores correspondentes de peso de polpa de banana $v s$ bala de banana produzida.

O rendimento médio de $28,69 \%$ obtida da transformação de diferentes quantidades de polpa de banana em bala (Figura 2) diferiu dos resultados obtidos por HUALLA (1993), que obteve um rendimento de $58 \%$. No entanto, é importante observar que o autor utilizou uma pequena quantidade de matéria prima (apenas $6 \mathrm{~kg}$ ) e empregou uma série de procedimentos laboratoriais que diferem bastante dos procedimentos empregados na UTPA Batuva, como: trituração da polpa de banana; pré-cozimento da massa em estufa a 105 ${ }^{\circ} \mathrm{C}$ durante 20 minutos; adição de $45 \%$ de açúcar a massa pré-cozida até a temperatura de $108,5 \stackrel{\circ}{ } \mathrm{C}$ por 30 minutos; e adição de $0,6 \%$ de ácido cítrico. A quantidade de açúcar adicionada por HUALLA (1993) também superou muito as formulações testadas no presente estudo (Tabela 1).
De forma análoga, porém utilizando os dados de peso de banana in natura e os dados de produção de bala (Tabela 1), chegou-se a relação de produção em peso, bala de banana vs banana in natura, apresentada na Figura 3. A referida relação também seguiu uma equação de regressão linear ( $Y$ $=0,1734 X+1,9767)$, com $R^{2}$ igual a 0,7669. Desta forma, pode-se dizer que $100 \mathrm{~kg}$ de banana in natura possibilidade a produção de $19,31 \mathrm{~kg}$ de bala de banana. O descarte da casca, cuja quantidade oscila, proporcionou a diferença verificada entre os dois coeficientes de determinação da regressão linear apresentados nas Figuras 2 e 3. A dispersão dos dados para a polpa de banana e banana in natura (Figura 1) refletem a variação causada pela remoção da casca.

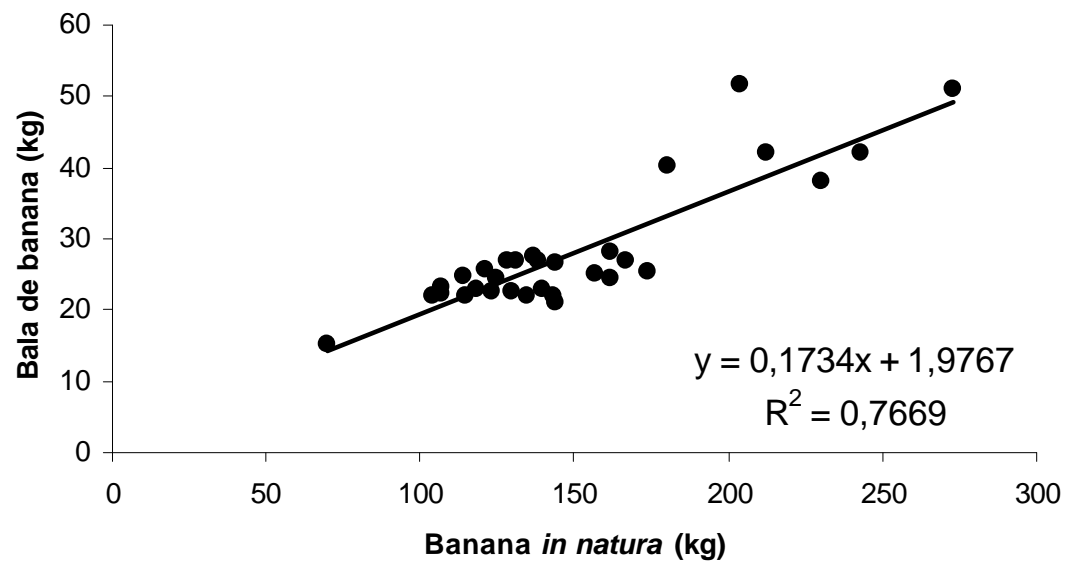

FIGURA 3 - Diagrama de dispersão obtido da relação entre os valores correspondentes de peso de banana in natura vs bala de banana produzida. 
A Tabela 1 apresenta os dados da série de testes (formulações avaliadas) com as diferentes quantidades e proporções entre ingredientes (quantidades de polpa de banana e açúcar). Os dados dispostos também permitiram determinar através de um diagrama de dispersão, a relação tempo de cozimento vs polpa de banana (Figura 4). Entre as equações de regressão analisadas, verificou-se que a equação polinomial $\left(Y=0,0306 X^{2}+7,7986 X+\right.$ $230,1)$ foi a que melhor explicou a dispersão dos dados relacionados. Porém, o coeficiente de determinação $\left(R^{2}=0,1201\right)$ obtido foi muito baixo, indicando que houve influência de fatores não controlados.

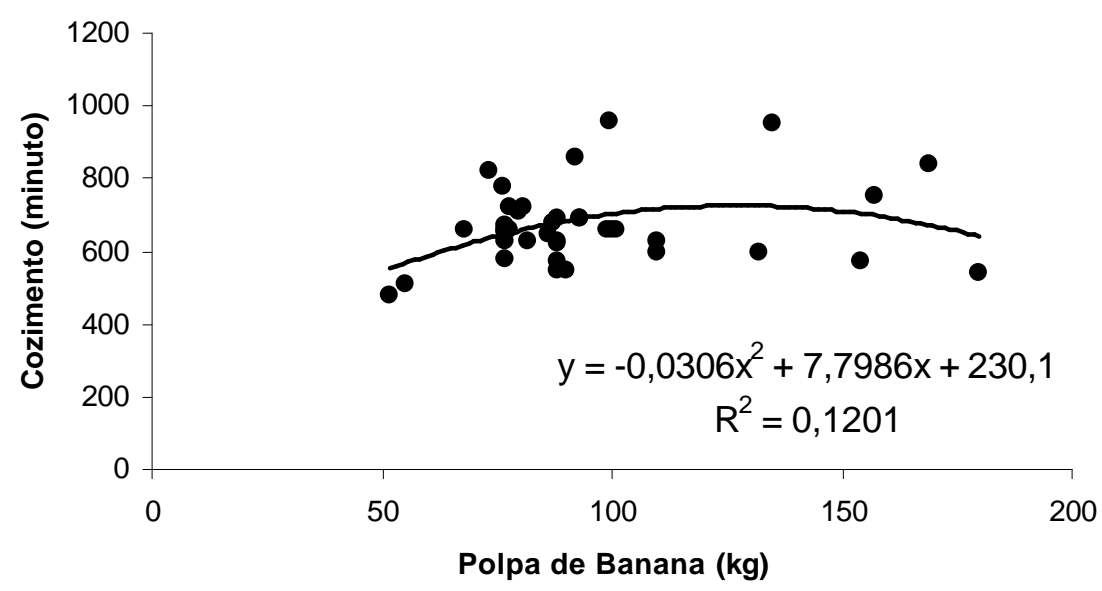

FIGURA 4 - Diagrama de dispersão obtido da relação entre dados de tempo de cozimento vs quantidade de polpa de banana.

BOBBIO e BOBBIO (1992) comentam que variações na proporção de ingredientes podem alteram a proporção entre açúcar, ácido e pectina, que por sua vez influenciam a formação do gel. Este fato pode explicar as mudanças no tempo de cozimento observadas nos resultados apresentados na Tabela 1 e Figura 4 . O uso de diferentes quantidades de material (polpa e açúcar) no mesmo tacho foi outro fator a alterar o tempo de cozimento e a produção de bala nos equipamentos por unidade de tempo. Além disso, o estudo realizado também utilizou frutas colhidas em diferentes épocas do ano, como verão e inverno, o que pode ter gerado diferenças em sua composição, fato já apontado por MACCARI e BITTENCOURT (1999). Do mesmo modo, a procedência da matéria-prima pode ter afetado os resultados. As propriedades rurais em Batuva mostram diferenças entre fatores como relevo e fertilidade do solo. Deste modo, tais variações podem ter influenciado as características da banana usada nos testes.
É importante observar ainda, que além da matéria-prima a metodologia experimental utilizada também pode explicar os baixos valores dos coeficientes de determinação $\left(R^{2}\right)$ para alguns parâmetros. As limitações de infra-estrutura laboratorial na unidade e o objetivo de desenvolver tecnologia para uso na agroindústria foram fatores considerados na escolha dos métodos empregados. Apesar das restrições decorrentes, foi possível identificar as melhores formulações.

Como os resultados apresentados na Figura 4 indicaram que a relação tempo de cozimento vs polpa de banana não segue tendência linear, verificou-se que tal tendência pode permitir a otimização do desempenho individual e global dos equipamentos, para toda a unidade. Desta forma, como um artifício para entender melhor a relação entre as variáveis, um novo diagrama de dispersão envolvendo a relação tempo de cozimento vs polpa de banana (Figura 5) foi realizado, porém, considerando a média dos agrupamentos conforme está apresentado na Tabela 2. 
MACCARI JÚNIOR, A. et al. Rendimento da produção de bala de banana...

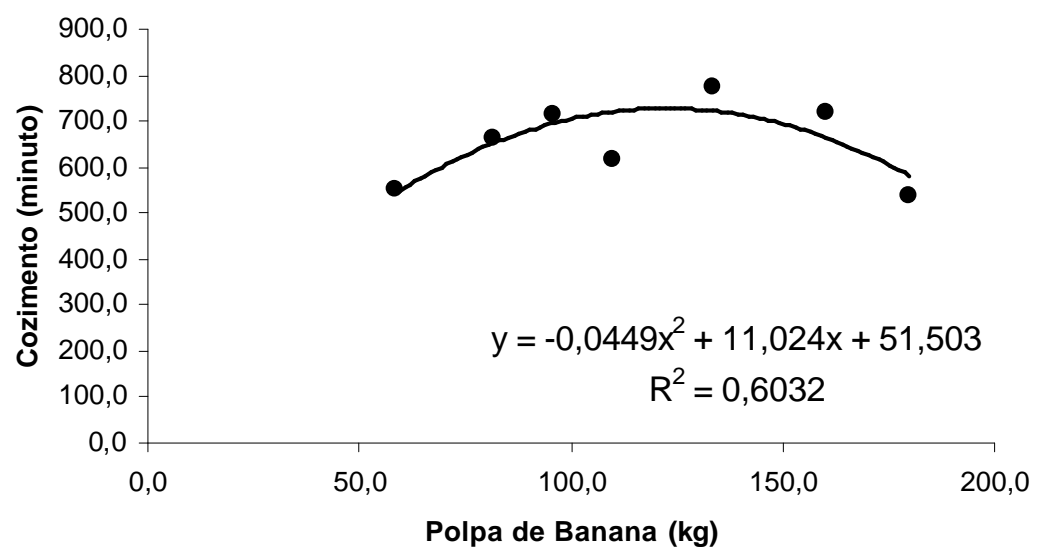

FIGURA 5 - Diagrama de dispersão obtido da relação entre dados agrupados de tempo de cozimento vs quantidade de polpa de banana.

TABELA 2 - Média dos agrupamentos de polpa de banana e tempo de cozimento dos testes 1 a 41 (Tabela 1), realizados na UTPA Batuba.

\begin{tabular}{|c|c|c|c|}
\hline \multirow[b]{2}{*}{$\begin{array}{l}\text { Intervalo de classe } \\
\text { (kg de polpa) }\end{array}$} & \multirow[b]{2}{*}{ Número de teste } & \multicolumn{2}{|c|}{ Média verificada no intervalo } \\
\hline & & Polpa de banana $(\mathrm{kg})$ & $\begin{array}{l}\text { Tempo de cozimento } \\
\text { (min) }\end{array}$ \\
\hline $50-70$ & 3 & 58,3 & 550,0 \\
\hline $70-90$ & $19^{*}$ & 81,4 & 663,6 \\
\hline $90-110$ & 8 & 95,9 & 715,6 \\
\hline $100 \mid-130$ & 2 & 110,0 & 615,0 \\
\hline $130 \mid-150$ & 2 & 133,5 & 775,0 \\
\hline $150-170$ & 3 & 160,0 & 720,0 \\
\hline $170-180$ & 1 & 180,0 & 540,0 \\
\hline
\end{tabular}

* Os testes concentraram neste intervalo devido à imprecisão sobre a real capacidade dos tachos

Uma análise visual da Figura 5 mostra, de forma geral, que o tempo de cozimento não foi diretamente influenciado pela variação na quantidade de banana em cada teste (carga do tacho). Desta forma, cargas maiores em cada tacho não implicaram em tempos maiores de cozimento. Para a nova disposição dos dados (Tabela 2), entre as equações de regressão analisadas, verificou-se que a equação polinomial $\left(Y=-0,0449 X^{2}+11,024\right.$ $X+51,503)$ continuou explicando melhor a dispersão dos dados relacionados, porém apresentando coeficiente de determinação $\left(R^{2}=\right.$ $0,6032)$ bem superior aos dados não agrupados $\left(R^{2}\right.$ $=0,1201$ ).

Os dados apresentados na Tabela 1, o agrupamento realizado na Tabela 2 e a capacidade projetada para cada tacho $(120 \mathrm{~kg})$, evidenciaram para os 6 testes empregando quantidade de polpa maior que $120 \mathrm{~kg}$ um rendimento médio de $13,8 \mathrm{~kg}$ de polpa $\mathrm{h}^{-1}$ (ou $3,93 \mathrm{~kg}$ bala $\mathrm{h}^{-1}$ ), enquanto os 35 testes que trabalharam respeitando o limite de até $120 \mathrm{~kg}$ tacho $^{-1}$ obtiveram um rendimento médio de $7,8 \mathrm{~kg}$ de polpa $\mathrm{h}^{-1}$ (ou 2,14 $\mathrm{kg}$ bala $\mathrm{h}^{-1}$ ).

A relação entre o rendimento (quantidade de polpa de banana tempo de cozimento ${ }^{-1}$ ) vs bala de banana foi uma outra análise interessante que os dados da Tabelas 1 permitiram realizar. A partir da Figura 6 é possível verificar que a relação entre 0 rendimento e as quantidades em peso de bala de banana segue uma equação de regressão linear ( $Y$ $=0,0015 X+0,0061)$, com coeficiente de determinação $\left(R^{2}\right)$ igual a 0,7647 . 


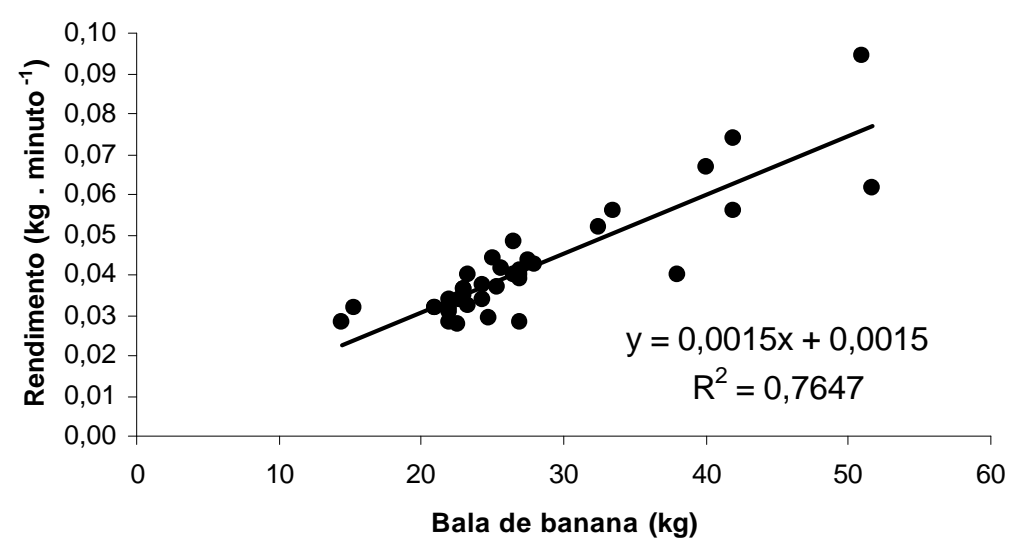

FIGURA 6 - Diagrama de dispersão obtido da relação entre dados de rendimento vs polpa de banana

As informações obtidas na Figura 6 são importantes, pois confirmam a tendência de aumento linear na quantidade de bala produzida com o aumento do rendimento (quantidade de polpa de banana tempo de cozimento ${ }^{-1}$ ). Assim, relacionandose as informações obtidas anteriormente, em que houve (a) aumento na produção de bala com o aumento da quantidade de polpa, (b) sem aumentar o tempo de cozimento, com (c) maior rendimento dos tachos a partir de cargas maiores; pode-se chegar a uma proposta de operação diferenciada do projeto original da unidade, observando que:

- Cada tacho localizado na Unidade de Transformação de Produtos Agrícolas de Batuva (UTPA Batuva) foi dimensionado para trabalhar com uma capacidade técnica de $120 \mathrm{~kg}$ de polpa de banana, no entanto, cargas superiores à projetada, aumentam o rendimento da estrutura e a capacidade produtiva;

- O sistema adequado seria trabalhar com cargas superiores à capacidade projetada para os tachos, gerando maior rendimento das atividades operacionais e diminuindo os custos na produção da bala. O fator restritivo, que deverá ser analisado nos próximos trabalhos para o redimensionamento do sistema, consistirá nas possíveis alterações sensoriais do produto, causadas pelas mudanças no tempo de aquecimento e na eficiência do conjunto para homogeneização da massa em cozimento.

Os resultados obtidos no presente estudo serão importantes no gerenciamento da produção de bala de banana na UTPA Batuva, e poderão ser empregados no planejamento da unidade. Baseandose no estudo inicial já realizado por SOUZA et al. (1999a), as atividades ligadas à produção e processamento da banana em bala na UTPA Batuva (área de plantio, quantidade de banana a ser produzida, dimensionamento do tamanho e número dos tachos, planejamento das operações de despencamento e descascamento) também poderão ser equacionadas e estudadas posteriormente empregando a programação linear, visto que todas as relações de rendimento estudadas seguiram tendências lineares, exceto a relação polpa de banana vs tempo de cozimento.

\section{CONCLUSÕES}

As informações coletadas e analisadas no presente estudo geraram vários coeficientes (relações entre quantidades) importantes para o gerenciamento da UTPA Batuva:

- As relações entre banana in natura vs polpa de banana, polpa de banana vs bala de banana e banana in natura vs bala de banana, seguiram tendências lineares. A relação polpa de banana vs tempo de cozimento correlacionou melhor com uma equação polinomial do segundo grau negativa.

- A banana cultivada em Batuva e as condições de funcionamento da unidade permitiram obter, em média, a produção: $66,7 \mathrm{~kg}$ de polpa de banana para cada $100 \mathrm{~kg}$ de fruta in natura; $28,69 \mathrm{~kg}$ de bala para cada $100 \mathrm{~kg}$ de polpa; e 19,31 kg de bala com 100 $\mathrm{kg}$ de banana in natura;

- Maiores rendimentos (polpa de banana tempo de cozimento $^{-1}$ vs bala de banana) foram obtidos quando se trabalha com a capacidade dos tachos acima do limite projetado. 


\section{REFERÊNCIAS}

1. BITTENCOURT, J.; QUEIROZ, M.R., NEBRA, S.A. Avaliação econômica da elaboração de banana-passa proveniente de cultivo orgânico e convencional. Engenharia Agrícola, v. 24, n. 2, p. 473-483, 2004

2. BOBBIO, F.O.; BOBBIO, P.A. Introdução a química de alimentos. São Paulo: Livraria Varela, 1992. p. 61-64.

3. CHACÓN, S.I.; VÍQUEZ, F.; CHACÓN, G. Physico-chemical profile of banana ripening. Fruits, v. 42, n. 2; p. 95-102, 1997.

4. FERREIRA, P. V. Estatística experimental aplicada à agronomia. Maceió: EDUFAL, 1991. 437 p.

5. HUALLA, L.A.C. Aproveitamento total de banana nanica (Musa cavendishii, L.) para a elaboração de balas e geléias. Curitiba, 1993. 80 f. Dissertação (Mestrado) - Universidade Federal do Paraná.

6. JESUS, S.C. de; FOLEGATTI, M.I. da S.; MATSUURA, F.C.A.U.; CARDOSO, R.L. Caracterização física e química de frutos de diferentes genótipos de bananeira. Bragantia, v. 63, n. 3, p. 315-323, 2004.

7. KOBIYAMAM, M.; MACCRI JR., A.; BITTENCORT, J.; BORDIGNON J.M.T. Agrotóxicos na cultura da banana em Batuva no município de Guaraqueçaba, Paraná. In: WALFLOR, M.F.G.M.; ZANONI, M.M. (Coords.) Desenvolvimento sustentável em Guaraqueçaba. Curitiba: Universidade Federal do Paraná, 1999. p. 133-143.

8. MACCARI JR., A.; BITTENCOURT, J. Unidade de transformação dos produtos agrícolas de Batuva, UTPA - Batuva: Parte 1 - Tecnologia de Produção para banana passa e bala de banana. In: WALFLOR, M.F.G.M.; ZANONI, M.M. (Coords.). Desenvolvimento sustentável em Guaraqueçaba. Curitiba: Universidade Federal do Paraná, 1999. p. 91-104.

9. PBMH \& PIF - Programa brasileiro para a modernização da horticultura \& produção integrada de frutas. Normas de Classificação de Banana. São Paulo: CEAGESP, 2006. (Documentos, 29).

10. PEREIRA, A.R.; ARRUDA, H.V. Ajuste prático de curvas na pesquisa biológica. Campinas: Fundação Cargil, 1997. $50 \mathrm{p}$.

11. PORCHERON, C. Criação de uma pequena unidade de transformação de produtos agrícolas em Batuva: apresentação do estudo de factibilidade. Curitiba: APB/ UFPR/ PROEC/ HOLOS. 1995. 10 p. (Relatório do Projeto de Desenvolvimento Sustentável em Guaraqueçaba).

12. RODRIGUEZ, R.M.H.P. Estudo de formulações de doce de polpa e/ou casca de banana, em pasta, com o uso de diferentes agentes branqueadores. Curitiba, 1994. 101 f. Dissertação (Mestrado) - Universidade Federal do Paraná.

13. SOUZA, J.L.M. de; MACCARI JR., A.; BITTENCOURT, J. Programação linear em uma agroindústria: planejamento, redimensionamento e maximização do lucro. O caso de Guraqueçaba-PR. Acta Scientiarum, v. 21, n. 3, p. 585-589, 1999a.

14. SOUZA, J.L.M. de; MACCARI JR., A.; SILVA, I.B. da. Unidade de transformação de produtos agrícolas da associação de pequenos produtores rurais de Batuva. In: WALFLOR, M.F.G.M.; ZANONI, M.M. (Coords.) Desenvolvimento sustentável em Guaraqueçaba. Curitiba: Universidade Federal do Paraná, 1999b. p. 75-89.

15. TAGLIARI, P.S. A agroindústria artesanal: uma conquista da dignidade e do valor da pequena agricultura familiar. Revista Agropecuária Catarinense, v. 10, n. 4, p. 30-37, 1997.

16. TSUCHIDA, F.M.; STELLA, F.M.; MACCARI JR., A. Análise dos principais atributos sensoriais de banana-passa. ENCONTRO REGIONAL SUL DE CIÊNCIA E TECNOLOGIA DE ALIMENTOS, 8., Curitiba, 2003. Anais. Curitiba, 2003. CD-ROM.

17. WALFLOR, M.F.G.M. A produção de conhecimento e formação em um projeto de extensão universitária: o caso Guraqueçaba. In: WALFLOR, M.F.G.M.; ZANONI, M.M. (Coords.). Desenvolvimento sustentável em Guaraqueçaba. Curitiba: Universidade Federal do Paraná, 1999. p. 19-40.

18. WALFLOR, M.F.G.M. Proposta de projeto de extensão: Desenvolvimento sustentável em Guaraqueçaba. Curitiba: UFPR/PROEC/HOLOS. 1994. 10p. (Relatório do Projeto de Desenvolvimento Sustentável em Guaraqueçaba).

19. WILLS, R.B.H.; LIM, J.S.K.; GREENFIEL, H. Changes in chemical composition of cavendish banana (Musa acuminata) during ripening. Journal of Food Biochemistry, v. 8, p. 69-77, 1984.

Recebido em 13/12/2005 Aceito em 20/06/2007 